\title{
CIDADES ARTIFICIAIS: UM ESTUDO EXPLORATÓRIO DO PROJETO URBANO PORTO ALEGRE 4D
}

Clarice M. de Oliveira ${ }^{1}$

\section{Resumo}

Uma cidade artificial é uma cidade projetada, criada do zero. Projetos contemporâneos de renovação urbana podem ser considerados projetos de cidade artificial pois o foco do projeto não está na população residente, ao contrário, desencadeiam processos de gentrificação e de atração de população externa. $\mathrm{O}$ objetivo deste artigo é, portanto, mostrar o caráter prático operacional dos projetos urbanos desta natureza descrevendo o Porto Alegre $4 D$. Se trata de uma política de organização espacial de uma parte da cidade. $\mathrm{O}$ argumento enfatiza como a vida da população do quarto distrito é desvalorizada. O projeto não é feito para aquele lugar e menos, ainda, para as pessoas que lá residem, mas sob a aparência de um desenho técnico beneficia grupos e setores econômicos.

Palavras-chave: Projetos urbanos. Cidades artificiais. Gentrificação. Produção do espaço.

\section{ARTIFICIAL CITIES: AN EXPLORATORY STUDY OF THE URBAN PROJECT PORTO ALEGRE 4D}

\begin{abstract}
An artificial city is a designed city, created from scratch. Contemporary projects of urban renewal can be considered an artificial city project because its focus is not on the resident population, on the contrary, they trigger processes of gentrification and attraction of external population. The objective of this article is, therefore, to show the operational-practical nature of urban projects of this kind, describing the Porto Alegre 4D project. It is a policy of spatial organization of the one part of the city. The

\footnotetext{
1 Mestre e Doutoranda em Planajamento Urbano e Regional - UFRGS. E.mail: arq.clarice@gmail.com Revista Brasileira de Estudos Organizacionais · v. 3. n. 1, p. 77-99, jun.2016, eISSN: 2447-4851 Doi 10.21583/2447-4851.rbeo.2016.v3n1.74 Sociedade Brasileira de Estudos Organizacionais
} 


\section{CIDADES ARTIFICIAIS: UM ESTUDO EXPLORATÓRIO DO PROJETO URBANO \\ PORTO ALEGRE 4D \\ Clarice M. de Oliveira}

argument the ways in which the life of the population of the fourth district is devalued. The project is not for this place and, even less, for the people who live there, but under the appearance of a technical design, for the benefit of economic sectors and groups.

Keywords: Urban Projects. Artificial Cities. Gentrification. Production Of Space.

\section{TÍTULO EM ESPANHOL}

Ciudades artificiales: un estudio exploratorio del Proyecto Urbano Porto Alegre 4D

\section{Resumen}

Una ciudad artificial es una ciudad diseñada, creada a partir de cero. Proyectos de renovación urbana contemporánea pueden ser consideradas como este tipo de proyecto con el foco en los procesos de gentrificación de disparo y la atracción de población extranjera. Por lo tanto, el propósito de este artículo es mostrar el carácter práctico-operativo de los proyectos urbanos de esta naturaleza, describiendo el proyecto Porto Alegre 4D. Se trata de una política de organización espacial para una parte de la ciudad. El argumento enfatiza cómo la vida de la populación del cuarto distrito es devaluada. El proyecto no es para aquel lugar y menos aún, para la gente que la reside, pero bajo la apariencia de un diseño técnico beneficia grupos y sectores económicos.

Palabras-clave: Proyectos Urbanos. Ciudades Artificiales. Gentrificación. Producción Del Espacio.

\section{Introdução}

Uma cidade artificial ${ }^{2}$ é uma cidade projetada, criada do zero, que após concluída pode receber moradores que não tem origem naquele lugar. Uma pesquisa rápida no Google mostra uma profusão de cidades

\footnotetext{
${ }^{2}$ Alexander (1966), defendendo o papel do planejamento urbano, faz a seguinte distinção: cidades que surgem espontaneamente e se desenvolvem ao longo dos anos são cidades naturais; cidades ou partes de cidades que são intencionalmente criadas por planejadores, são cidades artificiais. Mas, como diz o título do ensaio, cidades não são árvores. Esse é um claro exemplo do que Lefebvre (2008b) chama de 'senhores do espaço'.
} 


\section{CIDADES ARTIFICIAIS: UM ESTUDO EXPLORATÓRIO DO PROJETO URBANO \\ PORTO ALEGRE 4D \\ Clarice M. de Oliveira}

artificiais futuristas, baseadas na alta tecnologia para recriar o meio ambiente artificial em um grande edifício apresentado como uma cidade autossustentável, flutuante, e que, supostamente, não causaria danos ao ecossistema. Seguindo a lógica de uma cidade criada do zero, Brasília a cidade modernista projetada pelos arquitetos Lúcio Costa e Oscar Niemeyer também pode ser chamada de uma cidade artificial. Porém, este artigo não trata nem de uma cidade do passado e nem de uma cidade do futuro, trata do presente, momento em que se presencia a tendência dos projetos de renovação urbana como "o caminho dourado para a sobrevivência urbana" (HARVEY, 2006, p. 175), baseado em atividades de consumo e acumulação capitalista.

O objetivo deste artigo é mostrar o caráter-prático operacional dos projetos urbanos desta natureza. Para tanto, faz um estudo ainda exploratório do Masterplan Porto Alegre 4D, um projeto urbano concebido pelo setor privado em parceria com a Prefeitura Municipal de Porto Alegre (PMPA) e desenvolvido por uma equipe multidisciplinar da Universidade Federal do Rio Grande do Sul (UFRGS).

Esta primeira exploração se baseou em entrevistas com envolvidos na elaboração do projeto, análise de documentos e artigos de revistas e jornais, e observação participante em eventos de apresentação e discussão do projeto.

A escolha teórico-metodológica baseada na obra de Henri Lefebvre se justifica pois vivemos $\mathrm{o}$ fenômeno contemporâneo da "hipermercantilização da vida urbana" (BRENNER, MARCUSE e MAYER, 2012, p. 2). Fenômeno apontado, inicialmente como a mercantilização do espaço urbano, a partir dos anos 1960 e 1970 por Lefebvre (2001, 2008a), Castells (1977) e Harvey (2008). As formulações de Lefebvre estão subjacentes ou, mesmo, formalmente referidas por alguns dos autores mencionados. Além disso, constata-se que há uma tendência, no campo dos estudos críticos urbanos e dos estudos organizacionais, em recorrer à obra desse autor. Acredita-se que o retorno de Lefebvre decorre do avanço do sistema do capital, em busca de novos espaços de acumulação, sobre o espaço urbano. Portanto, se faz necessário aprofundar o estudo da obra de Lefebvre e verificar sua adequação, com as devidas mediações para analisar fenômenos contemporâneos.

Nas partes que seguem serão desenvolvidos: (1) uma revisão dos conceitos principais da obra de Lefebvre acerca do espaço urbano e da produção do espaço; (2) descrição do projeto Porto Alegre 4D; (3) considerações finais com insights a partir da tríalética do espaço.

É preciso reconhecer que os dois primeiros itens deste artigo estão muito separados. A intenção, até porque se trata de um estudo 
exploratório e de um projeto urbano em fase inicial, não é aplicar o referencial lefebvriano para análise das informações sistematizadas na sequência. Sua presença serve, nesta versão do estudo, para que o leitor entenda o olhar que é dado ao projeto urbano, porque sua descrição tem o conteúdo que tem, e porque algumas interpretações estão ali colocadas. Ainda assim, espera-se contribuir na direção de uma maior aproximação entre os campos do planejamento urbano e dos estudos organizacionais, já que o tema da organização da cidade e da produção de políticas públicas referidas especificamente ao urbano se beneficia muito desta aproximação interdisciplinar.

\section{A produção do espaço urbano}

Para Lefebvre (2008b), o espaço não é produto, não é objeto, não é mercadoria, não é simplesmente um instrumento. Para o autor, a problemática do espaço vivido, em oposição ao espaço "neutro", puramente epistemológico, é um aspecto essencial do conhecimento da realidade urbana. Em relação a essa questão, Lefebvre (2008b) explora diversas hipóteses. Na primeira, "o espaço é a forma pura", conceito que exclui a ideologia, a interpretação e o não saber. $O$ espaço seria, nessa ótica, capaz de articular "o social e o mental, o teórico e o prático, o ideal e o real" (LEFEBVRE, 2008b, p. 41). Entretanto, tal hipótese implica a liquidação do tempo histórico, além de pesar sobre a cientificidade abstrata e o saber absoluto. Ela tem profunda relação com o urbanismo modernista e sua crítica: momento de valorização absoluta do saber científico, em que arquitetos e urbanistas acreditavam mudar o social através da forma. Lefebvre os chamou de "senhores do espaço". Ou seja, a forma concebida pelo técnico seria, depois, povoada pelos usuários que se comportariam de acordo com o recipiente em que estivessem envoltos. Nesse sentido, essa noção exclui o espaço histórico e vivido.

Em outra hipótese, o espaço é social, um produto da sociedade, ele resulta do trabalho e da divisão do trabalho sendo, pois, o lugar geral dos objetos produzidos. O espaço é, então, uma objetivação do social. Confrontando tais formulações, Lefebvre (2008b, p. 44) conclui que o espaço não é nem ponto de partida, nem ponto de chegada, "mas um intermediário em todos os sentidos desse termo, ou seja, um modo e um instrumento, um meio e uma mediação". O espaço é um instrumento político intencionalmente manipulado por um indivíduo ou um coletivo que detém poder sobre ele, e que o transforma conforme seus objetivos. "Nessa hipótese, a representação do espaço sempre serviria a uma estratégia, sendo ao mesmo tempo abstrata e concreta, pensada e desejada, isto é, projetada" (LEFEBVRE, 2008b, p. 44). O espaço é, então, carregado de ideologia e saber técnico. As representações do espaço servem, nesse sentido, para criar consenso e controlar as contradições inerentes ao modo 
de produção capitalista (LEFEBVRE, 1991). Assim, o saber técnico legitimado para produzir a representação do espaço se transforma no poder de transformar ideias e sentimentos, ou seja, no poder de criar o consenso acerca do espaço. Essa dominação racional-funcional vincula-se à reprodução da força de trabalho pelo consumo, sendo o espaço "o meio e o modo, ao mesmo tempo, de organização do consumo na sociedade neocapitalista" (LEFEBVRE, 2008b, p. 46).

Para Lefebvre (2008b, p. 46), “[...] as cidades são tão somente unidades de consumo correlatas às grandes unidades de produção". A essa formulação se incorpora a teoria da alienação: o espaço instrumental se torna abstrato a partir de uma falsa representação de vocação estratégica, passando a ser "um lugar fora do tempo, da vida e da práxis". O espaço assume a forma de mercadoria, em que, "no limite [,] não há mais exatamente ideologia, mas somente a falsa consciência, com os discursos que ela engendra".

Entretanto, o autor alerta que essa hipótese servia ao capitalismo concorrencial do século XIX, cujo enfoque recaia na reprodução dos meios de produção. Ao se renovar, o capitalismo incorporou a "reprodução das relações de produção" que se efetuam através da cotidianidade e dos momentos de lazer e cultura. Essa noção é complementar à última hipótese apresentada, mas leva a outra, mais complexa: “o espaço estaria essencialmente ligado à reprodução das relações (sociais) de produção" (LEFEBVRE, 2008b, p. 48). É o espaço da produção, ao mesmo tempo abstrato-concreto, homogêneo e desarticulado:

Essa reprodução se realiza através de um esquema relativo à sociedade existente, cujo caráter essencial é ser conjunta-disjunta, dissociada, mantendo uma unidade, a do poder, na fragmentação. Este espaço homogêneofraturado não é somente o espaço global do planejamento ou o espaço parcelar do arquiteto e dos promotores imobiliários, é também o espaço das obras de arte, por exemplo, o do mobiliário e do design. É o esteticismo que unifica os fragmentos funcionais de um espaço deslocado realizando, assim, seu caráter homogêneo e fraturado (LEFEBVRE, 2008b, p. 49).

Retoma-se, nesse ponto, a já citada noção de Harvey (2011) sobre a sedução pelo embelezamento e os símbolos de distinção social. Espaços homogêneos, com uma estética específica, criados em recortes, em partes fragmentadas no tecido urbano, tornam-se centros ou subcentros de consumo, polos de atração de uma determinada classe social, causando estranheza e constrangimento às demais classes e interferindo diretamente no poder do espaço, assim como na dinâmica da estrutura urbana. 


\section{CIDADES ARTIFICIAIS: UM ESTUDO EXPLORATÓRIO DO PROJETO URBANO \\ PORTO ALEGRE 4D \\ Clarice M. de Oliveira}

Ao propor o método que possibilita uma análise da produção do espaço, o autor apontou para a necessidade de esclarecimento destes dois termos. A noção de espaço já foi aqui esclarecida (ele é um produto da sociedade que resulta do trabalho e da divisão do trabalho). Sobre o conceito de produção, Lefebvre (1991) segue as indicações de Marx na associação de dois significados inseparáveis. Em um deles, os homens produzem a própria vida, sua própria consciência e seu próprio mundo ao transformar a natureza. No outro, a produção está relacionada diretamente ao trabalho e a produção de um objeto, um produto. Esta abordagem relaciona a produção diretamente com a vida cotidiana. Assim produção, produto e trabalho são abstrações concretas que tornam possível as relações de produção. Mas, Lefebvre (1991) quer ir além, defendendo que é preciso definir de maneira mais rigorosa as relações dialéticas entre produção e produto, trabalho e produto, e natureza e produção. Logo, o autor esclarece: o trabalho é insubstituível, sendo um produto é algo que pode ser reproduzido tal e qual, repetidas vezes; a natureza cria, não produz, por isso, um espaço natural intocado não é o espaço produzido. Em síntese, a humanidade cria trabalho e produz objetos e, nesse processo, os seres humanos se produzem.

Portanto, para Lefebvre (1991) se o conceito de produção transcende a oposição filosófica entre objeto e sujeito, como poderia a racionalidade inerente à produção ser definida? O próprio Lefebvre (1991, p. 69) responde: a produção "organiza uma sequência de ações com certa objetividade em vista (por exemplo, um objeto a ser produzido). Esta condição impõe uma dimensão temporal e outra espacial sobre as relações pelas quais os resultados são coextensivos". Portanto, para Lefebvre (1991), no momento em que ocorre uma atividade orientada para certo objetivo, se estabelece a relação tridiática entre os elementos espaciais (o corpo), os materiais (pedra, madeira etc.) e os dispositivos (linguagem, ferramentas, agendas etc.). Esta relação é o fundamento do desenvolvimento denominado de tríade da produção do espaço. Nela, se relacionam dialeticamente: o espaço percebido (a prática do espaço); o concebido (a representação do espaço); e o vivido (os espaços de representação) - sendo imprescindível que os três sejam analisados articuladamente. Lefebvre (1991) ressalta a importância dos espaços públicos, aqueles sem o consumo organizado e direcionado, onde todos têm o direito de ir e vir, estar e permanecer, sem constrangimentos, onde tal triplicidade pode ser percebida sem interferências. Em A revolução urbana, Lefebvre (2008a) já esboçava o que chamou mais adiante de espaçologia - uma teoria unitária do espaço:

[...] o conhecimento do fenômeno urbano só pode se constituir como ciência na e pela formação consciente de uma práxis urbana suplantando, com sua racionalidade própria, a práxis industrial atualmente realizada. É nesse 


\section{CIDADES ARTIFICIAIS: UM ESTUDO EXPLORATÓRIO DO PROJETO URBANO \\ PORTO ALEGRE $4 D$ \\ Clarice M. de Oliveira}

processo complexo que a análise recorta 'objetos', ou constrói 'modelos', todos provisórios, passíveis de revisão, de crítica. O que supõe, em primeiro lugar, a mencionada confrontação entre ideologia urbanística e a prática urbana dos grupos e classes sociais; em segundo lugar, a intervenção de forças sociais e políticas; em terceiro lugar a liberação das capacidades de invenção, sem excluir o utopismo que mais se aproxime do imaginário puro. (LEFEBVRE, 2008a, p. 125)

A prática espacial (o espaço percebido) é a maneira dialética como sociedade e espaço se relacionam, por um lado a sociedade propõe o espaço, e por outro, o pressupõe, ou seja, o produz paulatinamente na medida em que o compreende e apropria. Lefebvre (1991, p. 38) questiona como seria a prática social na sociedade neocapitalista ${ }^{3}$. E responde: “a prática espacial é composta por uma associação muito próxima entre o espaço percebido, entre a realidade do dia-a-dia e a realidade urbana (as rotas e redes que conectam os lugares fora do trabalho, do lazer e da vida privada)". A representação do espaço (o espaço concebido) é o espaço dos arquitetos, urbanistas, planejadores, engenheiros, ou de todos aqueles "que identificam o que é vivido e o que é percebido para o que é concebido" (LEFEBVRE, 1991, p. 38). É o espaço da tecnocracia, aonde se estabelecem os regimes discursivos. $\mathrm{O}$ espaço representacional (o espaço vivido) é o espaço como ele pode ser, plenamente vivido, momentos do presente: "um espaço que é dominado e por vezes experimentado passivamente, espaços em que a imaginação tende a transformar e se apropriar" (Lefebvre, 1991, p. 39). O espaço de representação é qualitativo, fluido e dinâmico, pois é um espaço vivo; é o espaço dos símbolos, das imagens. A produção do espaço inclui, portanto, a produção material, a produção de conhecimento, e a produção de significado. Essas dimensões formam uma trialética unitária e contraditória, como explica Schmid (2012).

Para estabelecer as relações entre o percebido, o vivido e o concebido, algumas categorias de Lefebvre (1991, p.193) acerca da arquitetura do espaço são fundamentais. A primeira se relaciona ao espaço percebido e diz respeito a uma superimposição de certas relações sociais à estrutura e à forma urbana: (1) espaços acessíveis de uso comum - rotas ou caminhos, ruas, avenidas, em que o uso é pré-estabelecido seguindo certas regras de convívio; (2) limites e territórios proibidos - espaços nos quais o acesso é proibido relativamente (por vizinhos e amigos) ou

\footnotetext{
${ }^{3}$ A expressão sociedade capitalista é usada por Lefebvre para referir-se ao que ficou conhecido, a partir da escola da regulação francesa como pós-fordismo.
} 


\section{CIDADES ARTIFICIAIS: UM ESTUDO EXPLORATÓRIO DO PROJETO URBANO PORTO ALEGRE 4D \\ Clarice M. de Oliveira}

absolutamente (por vizinhos e inimigos); (3) locais de residência permanentes ou temporários; (4) pontos de junção - lugares de passagem ou encontro, geralmente têm o acesso proibido com exceção de ocasiões especiais - são momentos de declaração de paz ou guerra, por exemplo.

A segunda se relaciona ao espaço concebido e diz respeito ao espaço abstrato, Lefebvre (1991, p. 286-287) propõe a consideração de três formatos: (1) geométrico - tratado como 'absoluto', o espaço de referência, é o espaço euclidiano que se define por sua isotopia; (2) óptico ou visual o que é meramente visto, reduzido a uma imagem que torna difícil ver, mas que "é falado mais e mais eloquentemente e escrito mais e mais copiosamente"; (3) fálico - é completamente preenchido com imagens ou objetos transicionais que simbolizam a força, a violência masculina, a brutalidade do poder político e seus meios (polícia, exército, burocracia). Mas, diz ele, "o espaço não é homogêneo, ele apenas tem uma homogeneidade como meta, como orientação [...]. Ele parece homogêneo, mas é multiforme. Seus formatos geométricos e visuais são complementares em suas antíteses". Eles são "diferentes modos de atingir o mesmo resultado: a redução do 'real', por um lado, a um 'plano' existindo no vazio [...] e, por outro, à unidimensão de um espelho, de uma imagem, de puro espetáculo [...].

A terceira se relaciona ao espaço vivido e diz respeito às relações geralmente tratadas como psíquicas, mas que Lefebvre (1991, p. 186-187) prefere tratar como materiais, uma vez que surgem da conexão corpo/objeto e do espelho/ objeto. Por espelho, Lefebvre (1991) se refere ao processo de abstração que o objeto permite pelo reflexo do nosso corpo como um signo do que somos. Por meio desta relação disjunta entre forma e conteúdo, Lefebvre (1991) estabelece as seguintes classificações: (1) simetria (planos e eixos) - duplicação, refração, (as)simetria; (2) miragens e efeito miragem - reflexos da superfície versus profundidade, o revelado versus o oculto, o opaco versus o obscuro; (3) linguagem - mediação entre o implicador versus o implicado, ou entre o que confere valor versus o que tem valor, ou como mudança de direção através do discurso; (4) consciência - de si mesmo e do outro, do corpo e do ambiente abstrato dos outros e de tornar-se outro (alienação); (5) tempo - relação imediata entre repetição e diferenciação; (6) espaço - compreendendo as suas duplas determinações entre o imaginário e o real, o produzido e o produtor, o material e o social, o imediato e o mediato, o conectado e o separado.

Por fim, para definir as propriedades dos espaços urbanos diferenciais (tempo-espaço), o autor introduz novos conceitos: (1) isotopia - um lugar e tudo que o cerca e que faz de tudo o "mesmo lugar"; (2) heterotopia - uma diferença que situa o lugar diferencial com relação ao lugar inicial como um outro lugar e que pode ir do contraste ao conflito ao se levar em consideração os ocupantes do lugar; (3) u-topia - o não lugar 
que não tem lugar e busca um lugar para si. Nesse sentido, o u-tópico "não tem nada em comum com um imaginário abstrato". Ele é real, "ele está no próprio coração do real, da realidade urbana que não pode existir sem esse fermento. [...] Esse é um lugar paradoxal aonde o paradoxo se torna o oposto do cotidiano" (LEFEBVRE, 2003, p. 38).

Uma vez estabelecida a base teórico-metodológica da tríade da produção do espaço, a partir da qual foi construído o olhar sobre o projeto, a seguir se apresentam as informações sobre o Porto Alegre 4D.

\section{Porto Alegre 4D}

A região do $4^{\circ}$ Distrito de Porto Alegre é caracterizada geograficamente por sua proximidade com o centro da cidade na sua extremidade sul e conexão com a região metropolitana na extremidade norte. A região é muito bem servida por vias de acesso e serviço de transporte coletivo (ônibus e trem metropolitano), uma vez que importante infraestrutura de conexão metropolitana e regional passa por ali. Essa oferta de infraestrutura de mobilidade tem relação com o desenvolvimento histórico do $4^{\circ}$ Distrito. Desde o início do século XX, a região era ocupada por industrias do setor da fiação e metalurgia. No Plano Diretor de 1959 a região foi gravada como Distrito Industrial. Na época, o Plano seguia os preceitos modernistas da separação da habitação, lazer, trabalho e circulação por meio do zoneamento de atividades.

Com o passar do tempo, assim como em outras cidades brasileiras, houve a saída da indústria para fora das cidades, causando uma reestruturação nos usos da região. Atualmente, a região apresenta baixa densidade populacional (Figura 1), baixa ocupação por residentes com renda acima de cinco salários mínimos (Figura 2), e uma variedade de tipologias tombadas ou inventariadas pelo setor de patrimônio histórico. Segundo estudos estudos da Prefeitura Municipal de Porto Alegre (PMPA), a região apresenta um grande potencial de renovação imobiliária (Figura 4). 
Figura 1: Densidade demográfica (hab/Km2) do $4^{\circ}$ Distrito - Porto Alegre

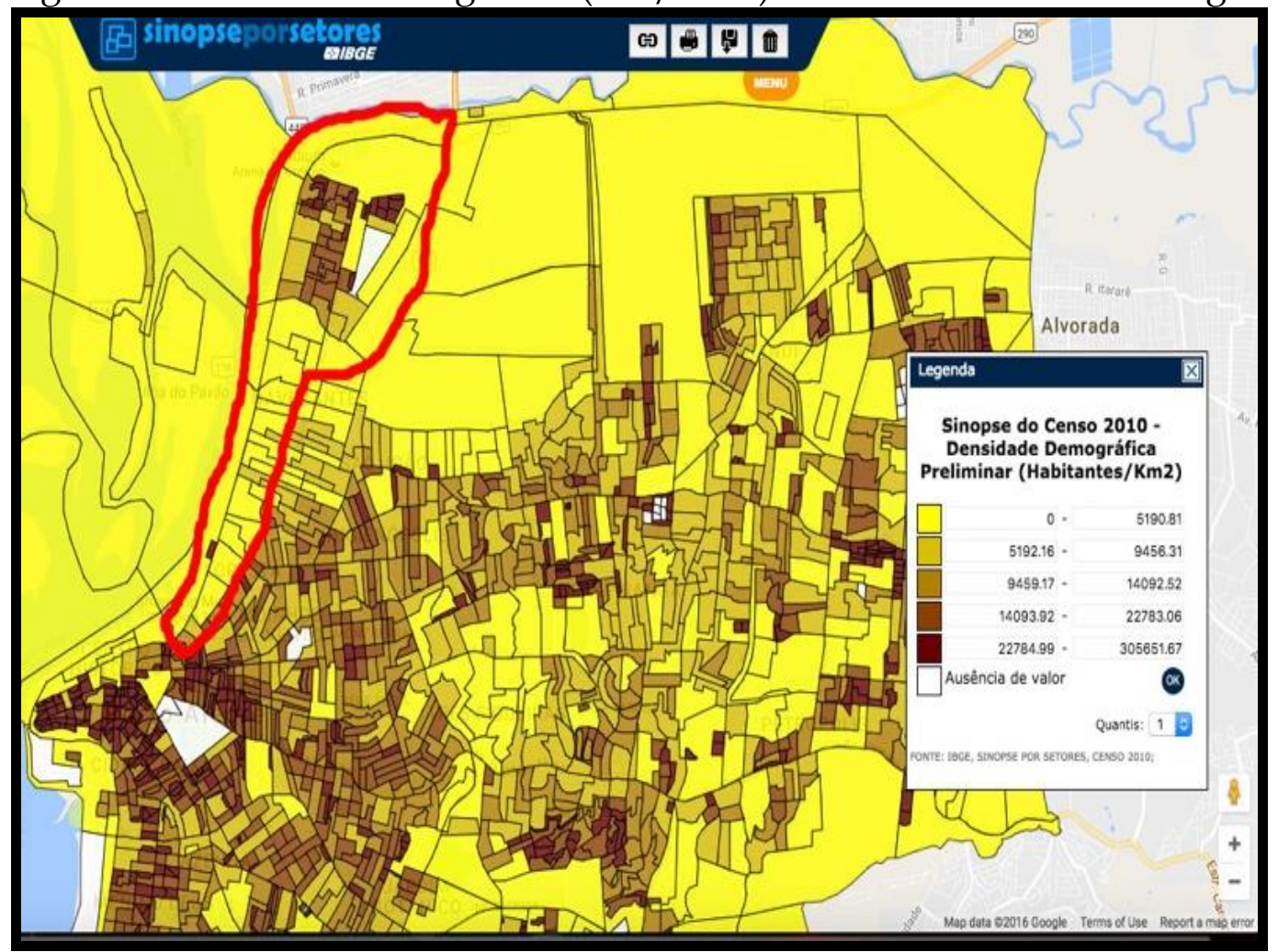

Fonte: IBGE (2010).

Figura 2: Renda per capita acima de 5 salários mínimos no $4^{\circ}$ Distrito Porto Alegre

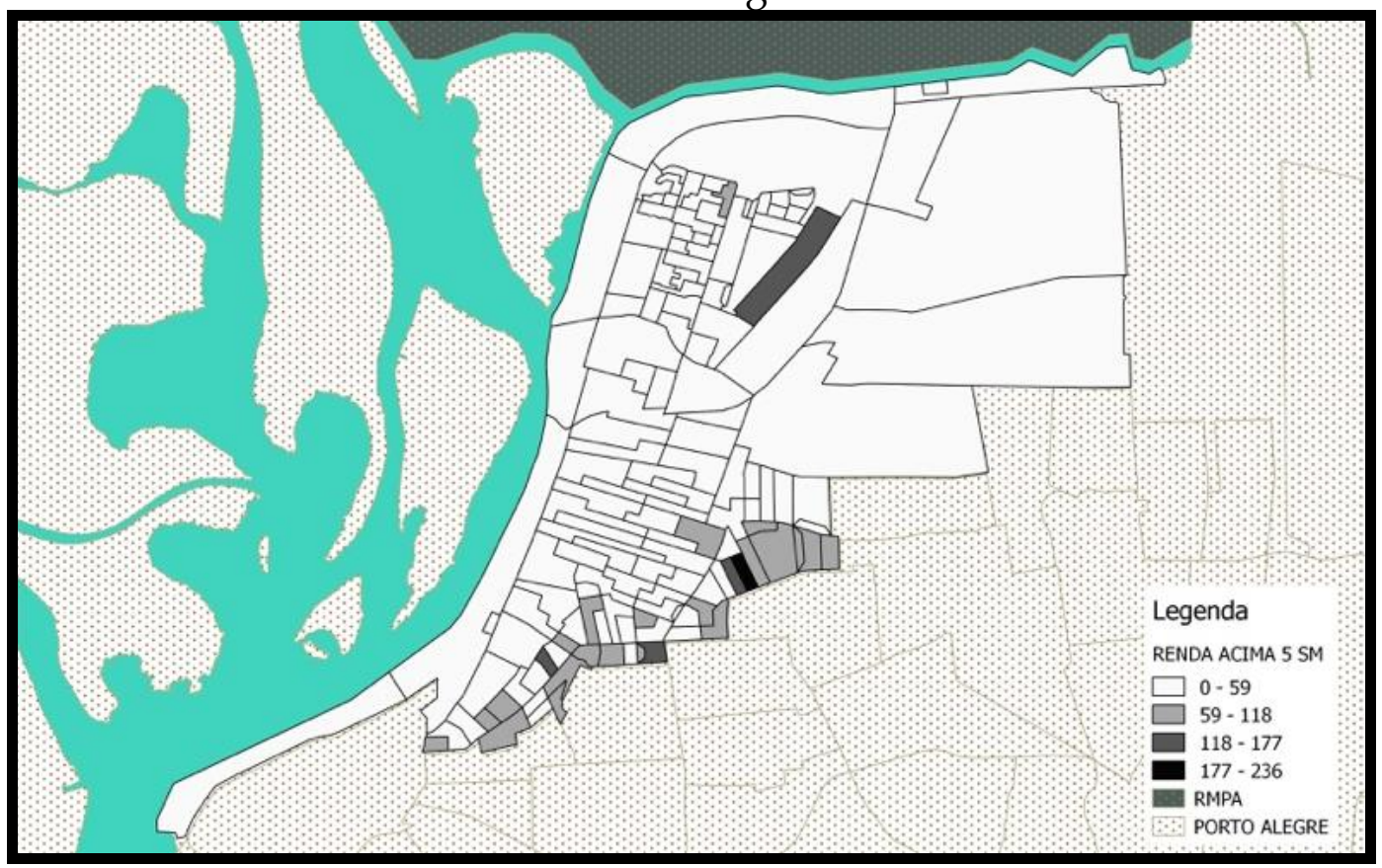

Fonte: IBGE ( 2010) 
Figura 3: Potencial de renovação construtivo no $4^{\circ}$ Distrito - Porto Alegre

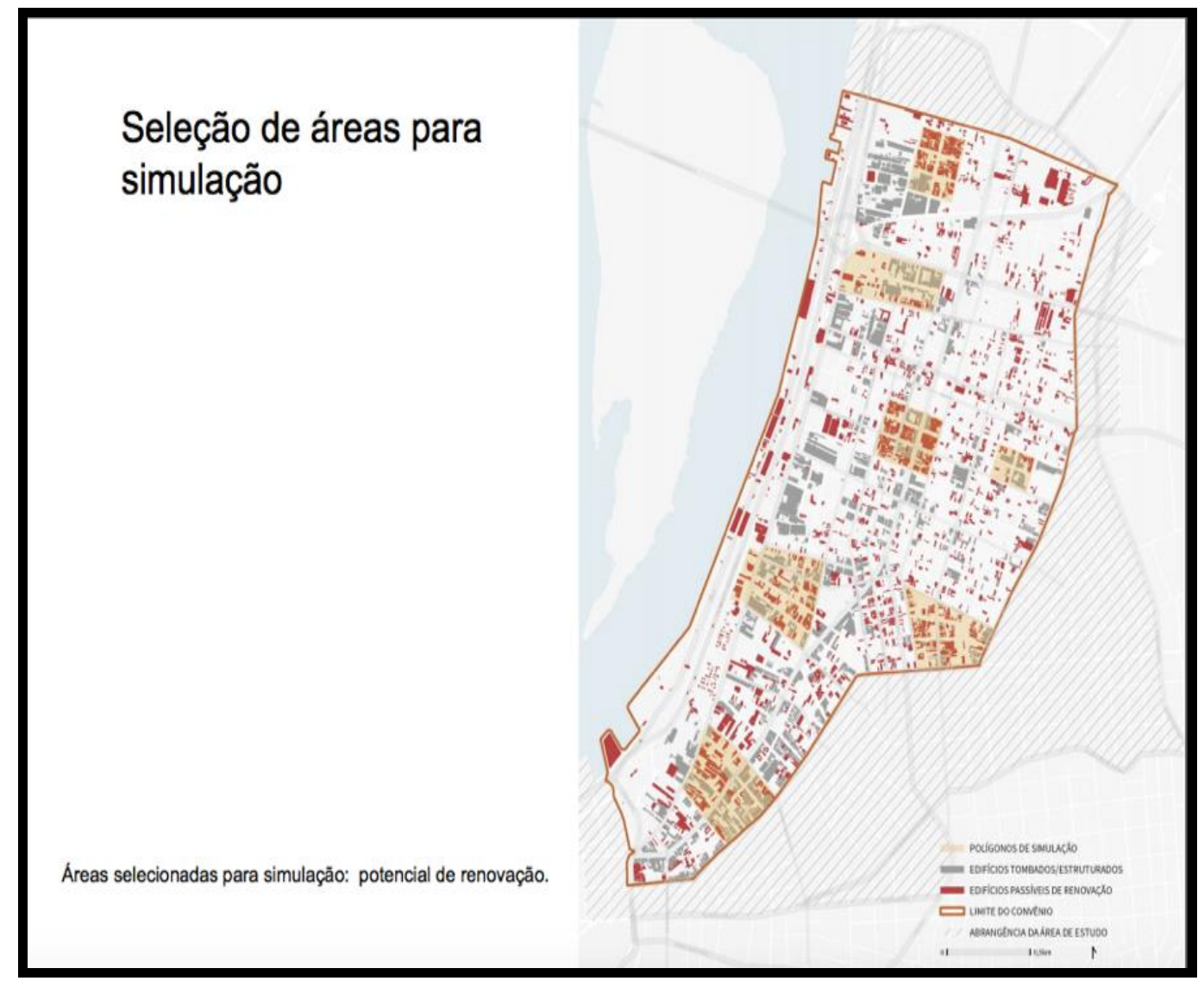

Fonte: Masterplan 4D (2016)

Os dados acima apresentados, associados ao discurso por parte dos envolvidos no projeto, indicam que a região do $4^{\circ}$ Distrito seria um lugar sem vida. A mídia reforça essa suposição:

Há pelo menos 30 anos o Quarto Distrito de Porto Alegre pede socorro. Após meio século de boom industrial, foi abandonado pelas fábricas, viu a degradação tomar conta de suas ruas e amargou o afastamento gradativo da vida urbana - agravado por alagamentos, insegurança e prostituição. Em meio a desacertos e desinteresse político, hoje iniciativas da sociedade civil tentam transformá-lo novamente em um espaço público vibrante (FELIN, 2014).

Na mesma reportagem, os presidentes do Conselho de Arquitetos e Urbanistas (CAU-RS) e do Instituto dos Arquitetos do Brasil (IAB-RS) alertam para a necessidade de planos claros para a área. Segundo o presidente do CAU-RS, "a partir do momento em que a prefeitura não apresenta um plano específico para a região, ela fica ao sabor dos 
interesses e precisa lidar caso a caso. Aí, às vezes, as obras são melhores para o investidor, às vezes melhores para a cidade" (FELIN, 2014). Importante notar que a matéria foi realizada pelo Jornal Zero Hora (vinculado ao Grupo RBS, filial da Rede Globo no Estado) quatro meses após a realização da Copa do Mundo em Porto Alegre, no momento de avaliação da experiência de grandes obras oportunizada pelo megaevento. Vale destacar que, por ocasião da realização da Copa do Mundo 2014, importantes obras de infraestrutura e equipamentos urbanos foram realizadas como a construção do novo estádio de futebol do Grêmio (na extremidade norte), o incremento da rede de fibra ótica, a duplicação de vias e o Grande Projeto Urbano, ainda em disputa, de Revitalização do Cais Mauá (na fronteira sul do $4^{\circ}$ Distrito) ${ }^{4}$.

Os incrementos de infraestrutura associados à localização privilegiada (centro da cidade, aeroporto e rodovias interestaduais) favorecem a perspectiva de 'revitalização' da área baseada no desenvolvimento de atividades de inovação e no empreendedorismo associados ao desenho urbano. Sobre a disseminação da ideia de revitalização para legitimar o projeto Porto Alegre 4D, vale ressaltar essa não é uma região vazia e sem vida. A Figura 4 elucida esta questão - as cores mais escuras representam a maior concentração de domicílios particulares permanentes não ocupados. Em contraposição, a Figura 5 mostra em cores mais escuras a maior concentração de domicílios particulares permanentes ocupados. A leitura das duas imagens relacionando-as com a Figura 2 propicia a compreensão de que, sim, a área tem uma ocupação mais rarefeita e apresenta alguma parcela de lotes desocupados, mas não configura um vazio urbano.

Figura 4: Domicílios particulares permanentes não ocupados

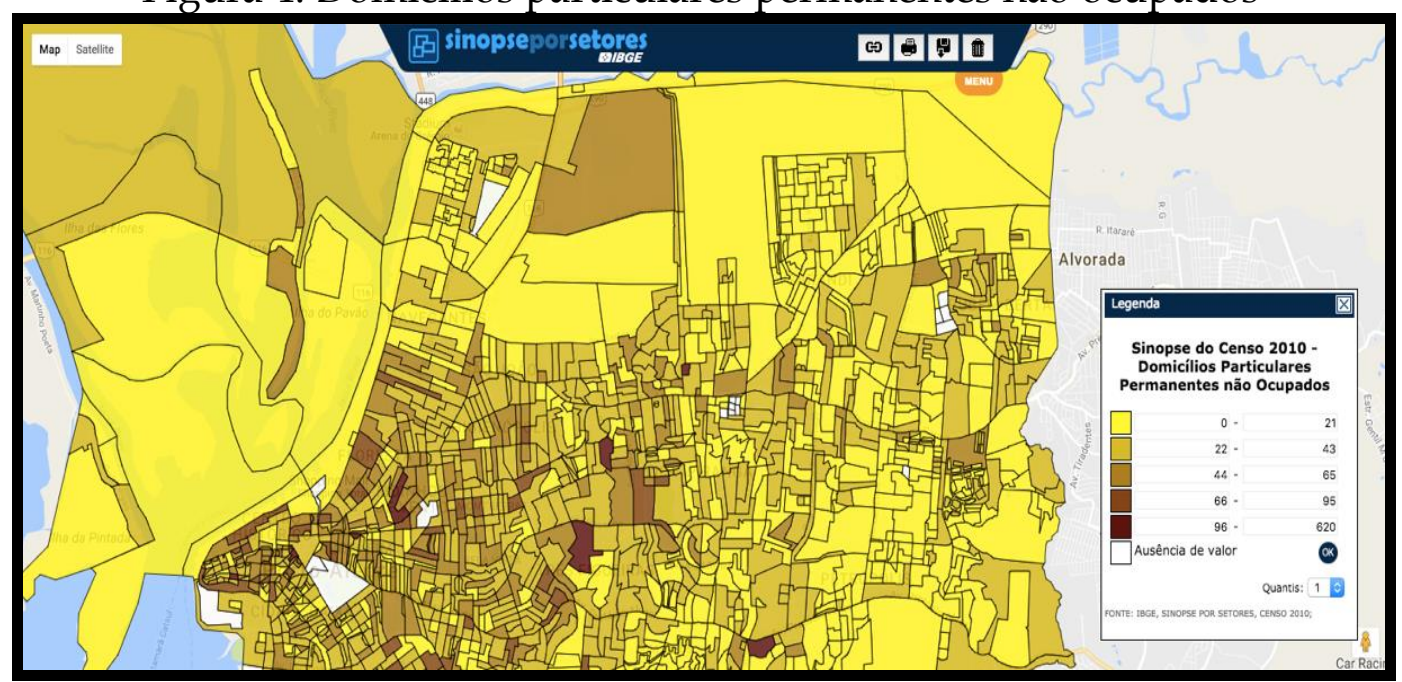

Fonte: IBGE (2010)

${ }^{4}$ A esse respeito ver: Oliveira, C. M.; Misoczky, M. C. Urban entrepreneurialism in FIFA World Cup host cities: the case of Porto Alegre. Organizações \& Sociedade v. 23, p. 624-645, 2016. 


\section{CIDADES ARTIFICIAIS: UM ESTUDO EXPLORATÓRIO DO PROJETO URBANO \\ PORTO ALEGRE 4D \\ Clarice M. de Oliveira}

Figura 5: Domicílios particulares permanentes ocupados

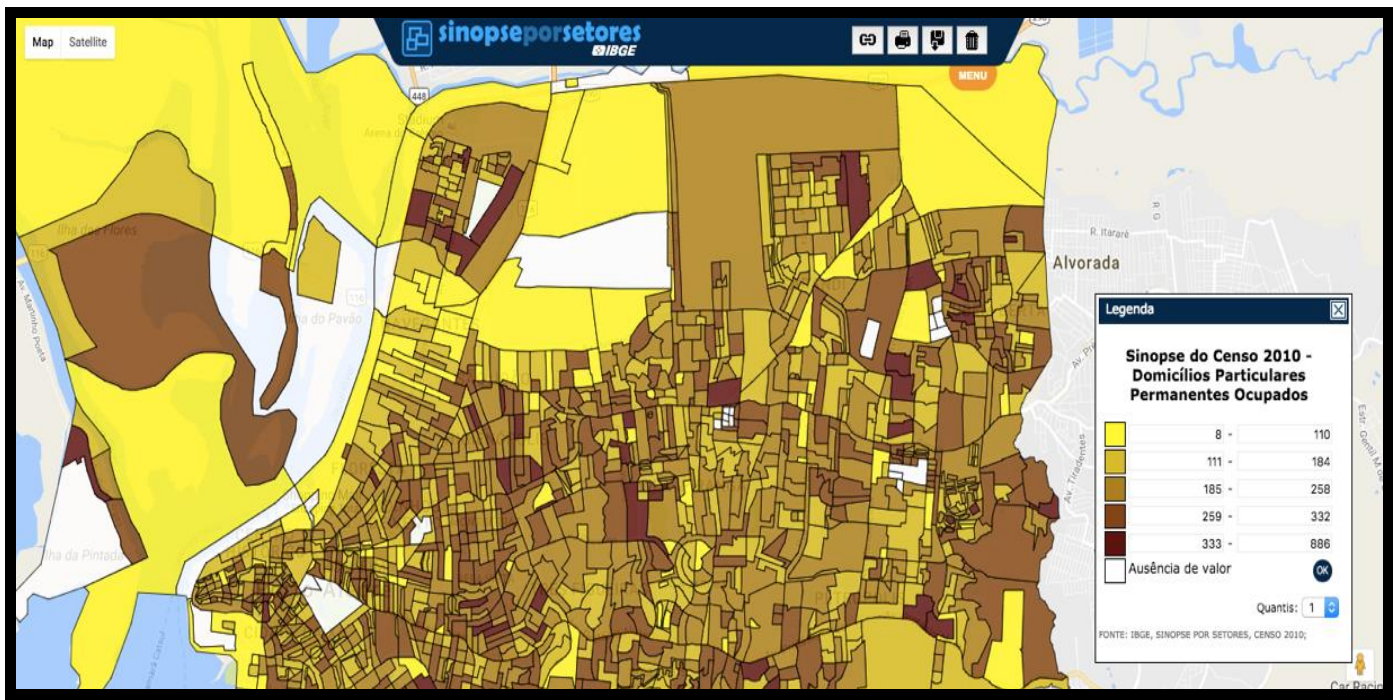

Fonte: IBGE (2010)

Percorrendo a região, por meio de espaços acessíveis ao uso comum como ruas e praças, percebe-se a diversidade do tipo de ocupação arquitetônica e da diversidade social. A região Norte dos Bairros Humaitá e Navegantes é ocupada por condomínios de classe média, todos cercados, por vilas urbanizadas e ocupações informais. Nesta parte do $4^{\circ}$ Distrito é onde se localiza o estádio de futebol Arena do Grêmio e as torres de apartamentos de classe média. É possível perceber neste cenário limites e territórios proibidos, originando segregação sócioespacial, seja pelos muros dos condomínios fechados que contam com estrutura de lazer intramuros, seja pelo preconceito, medo, ou falta de vontade de circular em favelas, mesmo que urbanizadas. Neste caso, os muros são invisíveis e construídos cotidianamente.

Seguindo em direção ao centro, o cenário é um pouco diferente, variando entre edificações de patrimônio histórico, galpões de indústria (alguns abandonados e outros em operação), habitações de classe média, cortiços, praças, terminais de ônibus, equipamentos públicos como escolas e abrigos da PMPA. A ocupação varia em áreas de tecido urbano mais ou menos consolidado, com mais ou menos comércio e com diferentes classes sociais.

A parte do Bairro Floresta é mais consolidada, por sua proximidade com o centro e o Bairro Moinhos de Vento, de classe média-alta. Nesta fração do território observa-se o convívio entre moradores, comerciantes, profissionais do sexo e, mais recentemente, jovens empreendedores que se alinham com o conceito de economia criativa. Por sua proximidade com a malha urbana consolidada e pelos ainda a baixos custos de aluguel, a região se tornou um atrativo para este público. 


\section{CIDADES ARTIFICIAIS: UM ESTUDO EXPLORATÓRIO DO PROJETO URBANO \\ PORTO ALEGRE 4D \\ Clarice M. de Oliveira}

A partir desta transformação recente o projeto, que tem como lema transformar o $4^{\circ}$ Distrito no lugar mais inovador da América Latina, começou a ser prospectado em meados de 2013, quando os participantes do grupo CITE (Cidadãos, Inovação, Tecnologia e Empreendedorismo ${ }^{5}$ ) organizaram uma viagem ao Vale do Silício. Na ocasião, foi uma comitiva de 30 pessoas incluindo o ex-Prefeito de Porto Alegre José Fortunati, os secretários de Governança Local e de Planejamento e os coordenadores do Gabinete de Inovação (Inovapoa) e de Gabinete Digital. Segundo o exPrefeito,

Porto Alegre é hoje, entre as 50 maiores cidades do Brasil, a segunda em criatividade e uma das que mais investe na indústria criativa e da inovação. Nós queremos consolidar a cidade como uma referência na área. E a ida ao Vale do Silício significa trazer investimentos, trazer mais esperança para o desenvolvimento desse importante setor para a nossa cidade. Sem contar que as novas tecnologias aprimoram a prestação de serviços e quem ganha com isso é a população, é o cidadão (FERNANDES, 2013).

A PMPA e o grupo CITE encontraram nas universidades parceiros interessados em compor o projeto, principalmente a Universidade Federal do Rio Grande do Sul (UFRGS) ${ }^{6}$ e a Pontifícia Universidade Católica (PUC-RS), que vislumbram a possibilidade de construir um parque tecnológico na área. Segundo um dos entrevistados envolvido no projeto, durante reuniões com o setor privado de tecnologia e inovação e universidades, as questões urbanas acabaram liderando muitas das discussões, uma vez que as empresas demonstravam a preocupação em investir em funcionários de alta qualidade, para em três ou quatro anos saírem em função de oportunidades de trabalho em outra cidade com mais atrativos urbanos.

Diante desta questão, em 2015, uma comitiva composta pelos então Prefeito e Secretários da PMPA e representantes do setor privado (construção civil, educação e saúde, principalmente) fizeram uma viagem a Barcelona para conhecer a experiência do 22@Barcelona. Segundo o ex-

5 Ver notícia sobre a criação do CITE:

http://www.baguete.com.br/noticias/13/05/2013/cite-quer-agitar-porto-alegre.

Chama atenção como se apresentam: "grupo formado por jovens empreendedores em tecnologia, profissionais referência na área empresarial e acadêmica querem romper o marasmo de Porto Alegre e colocar a capital de volta no cenário internacional de investimentos em inovação". Nada mais óbvio que definir uma área da cidade como sem vida, já que para esses 'jovens' (de fato, não tão jovens como se apresentam) toda a cidade é um marasmo.

${ }^{6}$ Nesta Universidade o projeto inclui o Núcleo de Tecnologia Urbana da Faculdade de Arquitetura e o Núcleo de Gestão da Inovação Tecnológica da Escola de Administração, entre outros. 
Secretário Municipal da Fazenda Jorge Tonetto, que coordenava o grupo junto com o ex-Secretário de Urbanismo, Valter Nagelstein, “nesta primeira fase do projeto está sendo discutido todo o equipamento urbano necessário para dar uma ambiência de qualidade ao local e atrair investimentos de empresas" (FERRAZ, 2015).

A mudança da coordenação do projeto para o ex-Secretário da Fazenda Jorge Tonetto representou um marco no desenvolvimento do projeto. Segundo um entrevistado, a Secretaria da Fazenda coordena o projeto pois é nela que se viabiliza economicamente a sua implementação. Ainda em julho de 2015 foram realizadas visitas técnicas em São Paulo e no Rio de Janeiro para conhecer as experiências das Operação Urbana Consolidada do Porto Maravilha e da venda de Certificados de Potencial Adicional de Construção (CEPACs). Em São Paulo as visitas foram na SP Urbanismo e no Banco do Brasil Investimentos.

Foram criados, então, mecanismos de incentivo fiscal e isenção de impostos para que empresas se interessassem pela área. Dentre as leis de incentivos aprovadas ainda em 2015 estão: isenção do IPTU por cinco anos (propriedade, locação ou cessão), isenção do ITBI na aquisição de imóveis para empresas de base tecnológica ou inovadora que venham a se instalar na região; redução de $5 \%$ para $2 \%$ na alíquota do ISS para pesquisa e desenvolvimento nas áreas de tecnologias da saúde em toda a cidade.

Além disso, a PMPA julgou oportuno utilizar o instrumento das Operações Urbanas Consorciadas (OUCs), à exemplo de São Paulo e Rio de Janeiro. Tendo em vista a venda de CEPACs para a região e a possiblidade da emissão de debêntures da dívida pública na bolsa de valores, a PMPA aprovou na Câmara de Vereadores o projeto de Lei que cria a Empresa de Gestão de Ativos do Município S.A. InvestPOA, a exemplo de São Paulo e Belo Horizonte. Para tanto, a PMPA coloca como garantia seu patrimônio, inclusive importantes equipamentos públicos e culturais da cidade. Embora a venda de CEPACs pareça ser a fórmula para o sucesso de uma OUC, experiências como a do Porto Maravilha no Rio de Janeiro demonstram que o setor privado não tem o interesse necessário para deslanchar uma operação deste porte. Neste caso, todos os CEPACs foram comprados pela Caixa Econômica Federal, ou seja, pelo setor público.

No caso de Porto Alegre, segundo um dos entrevistados, mesmo com todo este aprimoramento nos instrumentos financeiros, a resposta do setor privado também não foi favorável, pelo menos enquanto a área mantivesse suas características de degradação física e de vulnerabilidade social. Assim, a posição dos empresários tanto da construção civil quanto do setor de tecnologia e informação corroboram para a necessidade do redesenho desta parte da cidade. Para tanto, em 2016, a PMPA contratou uma consultoria da UFRGS para a realização de um Masterplan para o 4D. Sob coordenação do arquiteto e professor da Faculdade de Arquitetura, Benamy Turkienicz, o projeto foi entregue à PMPA no final de 2016. 


\section{CIDADES ARTIFICIAIS: UM ESTUDO EXPLORATÓRIO DO PROJETO URBANO \\ PORTO ALEGRE 4D \\ Clarice M. de Oliveira}

Durante o processo de elaboração do Masterplan uma série de workshops e palestras foram organizadas com diversos setores da sociedade, incluindo construção civil, empresas da área da saúde, as casas colaborativas associadas à economia criativa presentes na região, universidades, e workshops chamados de sociais, mas com uma presença inexpressiva da comunidade residente.

Segundo o projeto disponibilizado pela PMPA os objetivos do Masterplan 4D (2016) são: reverter o processo de degradação do 4D, oportunizando investimentos econômicos e sociais; preservar, valorizar e qualificar o patrimônio construído; incorporar agenda ambiental na cidade; melhorar a mobilidade e os padrões de acessibilidade urbana; intensificar a urbanidade no 4D e garantir ambientes amigáveis para todas as faixas etárias; incentivar a população habitacional inclusiva.

O projeto visa desenvolver áreas temáticas como clusters relacionados às áreas da saúde, ensino, tecnologia e indústria criativa. São incorporadas iniciativas já presentes no $4^{\circ}$ Distrito como as casas colaborativas de economia criativa e a Zona de Inovação Sustentável em Porto Alegre ZISPOA) dirigida por Marc Weiss presidente do Global Urban Development (GUD) que está presente em Porto Alegre desde 2013. Weiss foi responsável pela implementação do $\mathrm{NoMa}^{7}$ em Washington, onde foi realizada a renovação de uma zona industrial a partir de atividades envolvendo mídia e tecnologia. Associado ao ZISPOA está o projeto de Living Lab, a exemplo do 22@Barcelona. No Masterplan 4D, uma rua é programada como via da inovação para abrigar as ações e estudos de novas tecnologias associadas aos problemas urbanos, na lógica do que vem sido denominado de Smart Cities. É importante destacar que o trabalho de Weiss é financiado pelo Banco Mundial e que ele trabalha diretamente com estudantes das universidades locais em atividades sempre associadas ao empreendedorismo e à inovação configurando-se, também, como uma estratégia de difusão de práticas neoliberais. No entanto, segundo o ZISPOA, o projeto é elaborado pela comunidade e conta com iniciativas como a Pulsar e Next Citizens.

Outra estratégia do Masterplan se refere às chamadas quadras rápidas. Seriam quadras, ou até mesmo conjunto de quadras, que por pertencer a um mesmo proprietário ou por apresentar edificações sem uso de grande porte, teriam um alto potencial de transformação no curto prazo. A Figura 6 mostra os níveis deste potencial de transformação que

\footnotetext{
${ }^{7}$ Weiss é professor adjunto da área de Assuntos Internacionais e Públicos da Universidade de Columbia e professor internacional visitante de Economia e Administração de Empresas da Unisinos. Em 1998, ele foi autor de um Plano de Desenvolvimento Econômico para Washington e, especificamente, para a área norte de Massachusetts Avenue (NoMa), apresentado como uma oportunidade potencial de desenvolvimento em uma área enferrujada (sic), ancorada por empresas de mídia e acessível por uma nova estação de metrô (ver: http://www.revistadigital.com.br/2014/07/america-latina-precisa-de-um-vale-do-silicio/.).
} 


\section{CIDADES ARTIFICIAIS: UM ESTUDO EXPLORATÓRIO DO PROJETO URBANO \\ PORTO ALEGRE 4D \\ Clarice M. de Oliveira}

varia do mais rápido ao mais lento. Para as quadras rápidas são previstos Projetos de Intervenção Urbana (PIU), como são chamados no Masterplan, ou mesmo Grandes Projetos Urbanos (GPUs). São previstos pelo menos seis PIUs, tais como parque linear, shopping center, centro de cultura e centro administrativo.

Os estudos vinculados ao Masterplan são cruciais para o desenvolvimento dos novos parâmetros urbanísticos e para a venda de CEPACS. Estão ainda em fase de definição os estudos de volumetria que exploram novos índices de aproveitamento e ocupação dos lotes, sempre desde uma perspectiva da quadra. São exploradas questões de insolação e ventilação, bem como relação com o patrimônio. Segundo um dos entrevistados, chegaram a estipular uma altura máxima de seis pavimentos em quarteirões que contivessem edificações de patrimônio histórico. Porém, esta possibilidade foi contestada por técnicos da Secretaria da Fazenda, uma vez que os índices "baixos" não seriam atrativos para o desenvolvimento destas quadras. Turkienicz, autor do Masterplan, questionado em apresentações do projeto, argumenta que não haverá mudança na densidade prevista hoje no Plano Diretor para a região, mas que novos índices serão estipulados para determinados pontos respeitando a média de densidade máxima. A Figura 6 mostra os estudos volumétricos e os parâmetros urbanísticos previstos no projeto.

Figura 6: Simulações de ocupações de quadras

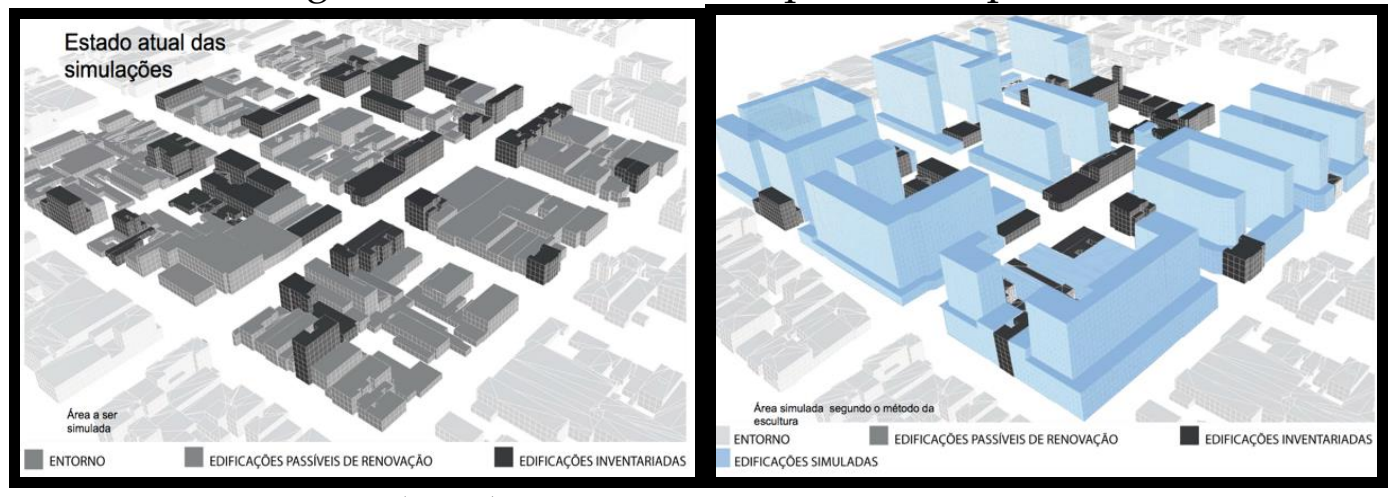

Fonte: Masterplan 4D (2016).

A única estratégia do Masterplan que se destina a tratar da população de alta vulnerabilidade social é estimular a produção de Habitação de Interesse Social (HIS) através de incentivos urbanos e fiscais. A responsabilidade da construção de HIS não seria do empreendedor, mas do Conselho Gestor que administrará os ativos e os recursos relacionados a OUC. O Conselho Gestor, assim como previsto no Estatuto da Cidade, terá competência de atribuir as prioridades e as ações necessárias para a implementação dos programas e projetos estabelecidos no Masterplan, assim como realizar contratos de administração para o cumprimento dos planos e metas estipulados. No Masterplan, este novo mecanismo de 


\section{CIDADES ARTIFICIAIS: UM ESTUDO EXPLORATÓRIO DO PROJETO URBANO \\ PORTO ALEGRE 4D \\ Clarice M. de Oliveira}

gestão é interpretado como uma estratégia de promoção da gestão participativa no desenvolvimento do território, uma vez que o conselho seria formado por quatro 'élices': PMPA, setor privado, universidades e sociedade civil organizada.

Cabe lembrar o caso do Porto Maravilha e o fato de que nenhuma das escolas e dos postos de saúde previstos foram construídos, pois os fundos destinados foram realocados para a construção do Museu do Amanhã. Para o $4^{\circ}$ Distrito, os entrevistados que participaram da elaboração do projeto não julgam que isso seria um problema, afinal se em um primeiro momento os investimentos necessários são para os projetos âncora, isto não significa que no futuro não possam ser realocados em projetos de caráter mais social.

Ainda no Masterplan 4D está prevista a localização de HIS de maneira pulverizada no território, a fim de evitar a criação de 'ghetos' como os hoje existentes. Se por um lado, no Masterplan é proposto um passo positivo com relação a esse problema; por outro, faltam mecanismos que evitem que esta estratégia sirva, na verdade, para a expulsão dos mais pobres da região. Aqui é preciso mencionar o projeto Porto Alegre Resiliente 8 , com financiamento da Fundação Rockfeller, que inclui no seu projeto estratégico, dentre outros programas, a revitalização do $4^{\circ}$ Distrito e a agilização do título de propriedade às famílias de baixa renda. A combinação título de propriedade para HIS e construções de alta qualidade pulverizadas no território só tem um resultado já suficientemente concretizado em tantas cidades: a gentrificação rápida e eficaz.

A articulação de um projeto urbano vai muito além do desenho arquitetônico, embora esta seja uma dimensão importante. Diferente da época do modernismo, a exemplo de Brasília, existe toda uma teia de articulações entre atores e instituições, e de instrumento de parcerias entre o setor público e o setor privado que vão além da forma urbana. Para a elaboração do projeto, a rede de atores que formam a coalisão para crescer, nos termos de Logan e Molotch (1993), pode ser facilmente percebida. Elites locais, políticos, grupos específicos das universidades e mídia corporativa formam esta coalisão. A população residente é colocada à margem deste processo, restringindo-se à presença em momentos e situações construídos para garantir a aparência de participação.

A presença de algumas menções a ações que seriam para a população residente e o discurso da reversão do processo de degradação do $4 \mathrm{D}$, oportunizando investimentos econômicos e sociais, quando detalhada mostra que o projeto desconsidera as necessidades desta população que, em última análise, não é o foco do projeto. Os tipos de investimento, o tipo de indústria e de usos não são os que se adequam à

\footnotetext{
${ }^{8}$ Ver: http://portoalegreresiliente.org/.
} 


\section{CIDADES ARTIFICIAIS: UM ESTUDO EXPLORATÓRIO DO PROJETO URBANO \\ PORTO ALEGRE 4D \\ Clarice M. de Oliveira}

qualificação capacitação profissional da população local. Como dito em diversas apresentações do projeto, a intenção é atrair uma população que hoje não tem interesse em morar ali, mas que, com os devidos atrativos de urbanidade, cultura e economia teriam vontade de ali se estabelecer.

Este fato é evidenciado não somente pelas declaradas intenções do projeto, mas pode ser percebido também no desenvolvimento do Masterplan. Abstrações que separam forma e conteúdo são recorrentes. As apresentações do projeto levam em consideração apenas a forma e a estrutura urbana.Em termos lefebvrianos, o espaço é tratado como geométrico, isotópico. Dados sócio-espaciais são negligenciados sistematicamente. Quando as equipes proponentes do projeto são confrontadas, por exemplo, com perguntas sobre habitação de interesse social, não sabem informar qual é a necessidade em termos quantitativos, menos ainda qualitativos. Entretanto, isto não impede o discurso de que o estoque de habitação social poderia servir não somente a população do território em questão, como também a de seu entorno. O discurso é reforçado por apresentações visuais, de cenários futuros. Em termos lefebvrianos, ele se demostra também fálico, representando a brutalidade com o que o Estado e o mercado pretendem se impor sobre os moradores da região.

Essas questões ficam evidentes em um espaço de junção, segundo categorização dos espaços vividos por Lefebvre (1991). Segundo o autor, somente nos espaços públicos é que a tríade da produção do espaço pode ser percebida na sua plenitude. Foi possível percebê-la no evento realizado no Espaço Cultural Vila Flores ${ }^{9}$ no dia 13 de setembro de 2016, com o nome Encontro Cidade: uma construção coletiva. O Vila Flores pode ser categorizado como um espaço de junção. Embora não seja público, ele é aberto ao público sistematicamente pela diversidade de atividades que abriga. É um ponto de encontro entre pessoas não só da região, mas da população da cidade em geral.

No evento promovido pelo Vila Flores o projeto foi apresentado pelo arquiteto coordenador do projeto urbano. No debate que se iniciou logo após a apresentação, moradores da região e de Porto Alegre confrontaram o projeto. Representantes do Movimento Nacional de Luta pela Moradia (MNLM), assistentes sociais da PMPA, coletivos de economia criativa estabelecidos na região, moradores, arquitetos e urbanistas, pesquisadores e militantes partidários estavam presentes. Todos defenderam que as imagens que apresentavam o projeto não expressam e nem contemplam os moradores da região. Primeiro, pelo uso da simetria. A leitura de apenas duas situações opostas, ou seja, assimétricas da região como um todo, são uma racionalização que oculta o conteúdo do lugar. Segundo, por uma questão de linguagem. As

\footnotetext{
${ }^{9}$ Ver: https://vilaflores.wordpress.com/about/.
} 
simulações em 3D expressam o que Lefebvre (2008a) denomina de espaço homogêneo e fraturado, disjunto. Homogêneo porque pasteuriza, é artificial, não é daquele lugar, é de qualquer lugar do mundo. Fraturado e disjunto porque não representa a linguagem de quem ali pertence e, por consequência, ao quebrar o sentimento de pertencimento do lugar, expulsa a população inclusive simbolicamente.

O fenômeno da gentrificação não se dá apenas pelo aumento do custo de vida (moradia, alimentação, conveniência, transporte etc.), mas pela exclusão do sentimento de pertencimento ao lugar. Segundo moradores presentes no evento, o projeto não se relaciona com a história do bairro, não a preserva nem valoriza. A relação harmônica entre o antigo e o novo perde para a geração de mais valia via capital imobiliário.

Pode-se dizer que os espaços culturais previstos, como as pequenas bibliotecas públicas (a exemplo das feitas em Medellín) e a Praça das Artes, que contariam com espaço para arte a capacitação profissional seriam respostas aos problemas sociais apresentados na região. Embora a difusão da cultura seja importante para todas as classes sociais, tal estratégia se alinha à noção do uso da cultura para promover o consumo a partir da imagem da cidade. Como visto a exemplo do Museu Guggenheim em Bilbao e do Museu do Amanhã no Rio de Janeiro.

\section{Considerações Finais}

A análise de um projeto urbano deve ir muito além da compreensão da dimensão da arquitetura em grande escala, sendo uma complexa relação de atores e processos a ele relacionado. Sendo assim, para garantir a harmonia social na produção de intervenções em territórios marcados pela contradição fundante do sistema do capital, é preciso ideologias bem sucedidas, como Lefebvre (2014) indica, ao referirse a ilusões efetivas. Ou seja, ideias que têm implicações práticooperacionais concretas.

No caso dos projetos urbanos, a ideia de que uma área precisa ser revitalizada se impõe como o indispensável carreador da cientificidade abstrata. Ainda que a crítica de Lefebvre (2008b) tenha sido feita para o urbanismo modernista, ela propicia inspiração para a crítica ao urbanismo neoliberal contemporâneo, já que arquitetos e urbanistas, agora com a colaboração dos gestores da inovação ('senhores do espaço' associados aos 'senhores da inovação'), continuam reproduzindo a lógica da forma concebida pelos técnicos que exclui, intencionalmente, o espaço histórico e vivido. Estes 'senhores' tomam o espaço como instrumento a ser intencionalmente manipulado conforme objetivos político-econômicos. As representações que produzem tentam criar consensos, transformar ideias e sentimentos (inclusive dos que vivem aquele espaço) e reorganizar o espaço como mercadoria a ser consumida e para o consumo. 


\section{CIDADES ARTIFICIAIS: UM ESTUDO EXPLORATÓRIO DO PROJETO URBANO \\ PORTO ALEGRE 4D \\ Clarice M. de Oliveira}

Assim se dissemina, por exemplo, a crença de que uma área precise ser revitalizada. Smith (2006) se refere à revitalização/renovação/regeneração urbana como um eufemismo alinhado à gentrificação generalizada como estratégia de planejamento. $\mathrm{O}$ eufemismo reside em fazer crer que os espaços delimitados para um determinado projeto urbano não têm vida e, portanto, precisam ser revitalizados. Claro, ter vida significa contribuir para processos cada vez mais intensivos de acumulação. A concentração de população de baixa renda na região do $4^{\circ}$ Distrito exemplifica esta situação, que pode ser percebida igualmente na área de outros projetos urbanos como a do Porto Maravilha. Assim, a gentrificação generalizada, nos termos de Smith (2006), alimenta a necessidade de gerar valor e, sobretudo, de valorização do valor associado aos processos cíclicos de produção-consumodistribuição-circulação. Para que isso ocorra sem perturbações, são necessárias representações do espaço que disseminem e criem consenso em torno da necessidade de revitalização urbana e, ao mesmo tempo, consolidam sua expressão contemporânea: o projeto urbano.

Percebe-se a transformação do papel do planejamento, de corretor dos problemas da cidade para empreendedor, ou seja, um instrumento que reforça o valor de troca e o consequente acesso desigual da população ao meio urbano. $\mathrm{O}$ arquiteto responsável pelo Masterplan 4D explicou em um debate sobre o projeto que "a cidade é uma mercadoria que precisa ser desenhada" (TURKIENICZ, 2016).

A cidade é meio de produção essencial para a reprodução das relações sociais de produção. Para garantir que esse meio se concretize efetivamente, os recortes urbanos que fragmentam o tecido do percebido e do vivido são indispensáveis. O Projeto Urbano Porto Alegre $4 D$ vem se mostrando, ainda que em fases iniciais, como um espaço de potencial conflito entre a prática espacial, a associação entre o espaço percebido, a realidade do dia a dia e a realidade urbana, daqueles que fazem do quarto distrito um território de vida e trabalho e a representação do espaço dos tecnocratas (aqui se usa livremente o termo cunhado por Lefebvre para se referir aso profissionais técnicos relacionados ao urbanismo para incluir, para além desses, os empreendedores, especuladores, acadêmicos, administradores públicos - a 'coalisão para crescer') que estabelecem os regimes discursivos que transformam o vivido e o percebido no concebido. A superimposição dos interesses destes 'senhores' está se produzindo através dos três formatos indicados por Lefebvre (1991): geométrico, visual e fálico. No entanto, a meta da homogeneidade, a redução do real a um plano, ao unidimensional, encontra, ainda que de maneira frágil no momento da escrita deste texto, a contraposição de lugares de encontro e de resistência, a introdução do paradoxal, a possibilidade da heterotopia e, quem sabe, da u-topia.

\section{Referências}


ALEXANDER, Christopher. A city is not a tree. Design, n. 206, p. 46-55, 1966.

BRENNER, Neil; MARCUSE, Peter; MAYER, Margit. Cities for people not for profit: an introduction. In: BRENNER, Neil; MARCUSE, Peter; MAYER, Margit (Eds.). Cities for People, Not for Profit: Critical Urban Theory and the Right to the City. New York: Routledge. 2012. p. 1-10.

CASTELLS, Manuel. The Urban Revolution: A Marxist approach. London: Edward Arnold, 1977.

FELIN, Bruno. Quarto Distrito espera há pelo menos 30 anos por uma revitalização. Jornal Zero Hora, Porto Alegre, 15 nov. 2014. Disponível em: (http://zh.clicrbs.com.br/rs/porto-alegre/noticia/2014/11/quartodistrito-espera-ha-pelo-menos-30-anos-por-uma-revitalizacao4643635.html), acesso em 29 jan. 2017.

FERNANDES, Melina. Fortunati parte em missão oficial ao Vale do Silício. Notícias do Portal da PMPA, Porto Alegre, 21 mai. 2013. Disponível em: (http://www2.portoalegre.rs.gov.br/portal_pmpa_novo/default.php?p_ noticia $=160745 \&$ FORTUNATI+PARTE+EM+MISSAO+OFICIAL+AO+VA LE+DO+SILICIO), acesso em 30 nov. 2016.

FERRAZ, Fernanda. Parques tecnológicos de Barcelona são modelo para o $4^{\circ}$ Distrito. Notícias do Portal da PMPA, Porto Alegre, 22 jun. 2015 Disponível em: (http://www2.portoalegre.rs.gov.br/portal_pmpa_novo/default.php?p_ noticia=178597\&PARQUES+TECNOLOGICOS+DE+BARCELONA+SAO+ MODELO+PARA+O+4O+DISTRITO), acesso em 30 nov. 2016.

IBGE. Censo Demográfico 2010. Disponível em:

(http://www.ibge.gov.br/home/estatistica/populacao/censo2000/), acesso em 30 jun. 2015.

MASTERPLAN 4D. 4D Distrito de Inovação de Porto Alegre. Porto Alegre, 21 de Dezembro de 2016. Disponível em:

(http://4distrito.portoalegre.rs.gov.br/sites/default/files/Masterplan_4D istrito.pdf), acesso em 13 de fev. 2017.

LEFEBVRE, Henri. The production of space. Oxford: Blackwell, 1991.

A revolução urbana. Belo Horizonte: Editora UFMG, 2008a.

. Espaço e política. Belo Horizonte: Editora UFMG, 2008b. 
LOGAN, John R; MOLOTCH, Harvey L. The City as a Growth Machine. In: FAINSTEIN, S. Susan; CAMPBELL, Scott. Readings in Urban Theory. Oxford: Blackwells, 1993.

HARVEY, David. Condição Pós-Moderna: uma pesquisa sobre as origens da mudança cultural. São Paulo: Loyola, 2011.

2006.

. A produção capitalista do espaço. São Paulo: Annablume Editora,

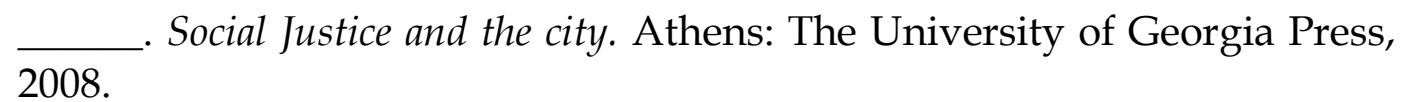

SCHMID, Christian. Henri Lefebvre, the right to the city, and the new metropolitan mainstream. In: BRENNER, Neil; MARCUSE, Peter; MAYER, Margit (Eds.). Cities for people, not for profit: critical urban theory and the right to the city. New York: Routledge, 2012. p. 42-62.

SMITH, Neil. A gentrificação generalizada: de uma anomalia local à "regeneração" urbana como estratégia urbana global. In: BIDOUZACHARIASEN, Catherine (Coord.) De volta à cidade: dos processos de gentrificação às políticas públicas de "revitalização" dos centros urbanos. São Paulo: Annablume Editora, 2006. p. 59-87.

TURKIENICZ, Benamy. Debate Ricardo Fayos e Benamy Turkienicz. Organização UrbsNova: Escolha de Engenharia da UFRGS, Porto Alegre 22 de dez 2016. Gravado. 